\title{
Researching Indoor Comfort of Teaching Buildings in Hot Summer and Cold Winter Area
}

\author{
Qi Zhang \\ School of Architecture,South China University of Technology, Guangzhou \\ Guangdong, China \\ rita.zq@foxmail.com
}

\begin{abstract}
Typical teaching spaces of the colleges in Chengdu are selected as the object of the research for its typical severe weather, which is hot in summer and cold in winter area climate. Several instruments have been utilized to test the index of thermal comfort, indoor temperature, wall temperature and air speed in teaching space in the winter. At the same time, the students' activity and their dress indoors during the winter have been invested by questionnaires survey. According to the test data and the survey results, the indoor physical environment problems and possible reasons were analyzed. Recommendations about the orientation, the window wall area ratio, shape coefficient, insulation of walls, doors and windows insulation and roof regenerative were provided for improving the environmental quality and promoting the work efficiency.
\end{abstract}

Keywords- teaching building; indoor physical environment; winter;promote; in hot summer and cold winter

\section{INTRODUCTION}

Indoor comfort is an essential part of building environmental science. Indoor comfort design, in accordance with the human body comfort requirements and local climate conditions, is one of the sustainable architecture design method. The essence is to adjust and process a variety of physical factors on construction in a reasonable way. Also fully understand human physical and mental requirements in the physiological aspects on internal and external environment of house, tune the local environment to benefit the human body comfort, and thus create an appropriate physical environment for people. Its ultimate goal is to improve the quality of architecture function and create a suitable living and working environment.

As the construction of economical campus were paid more and more attention, paying attention to indoor physical of the teaching space environment design is an effective measurement to optimize the teaching environment from the perspective of building in our country. The physical environment is an integral part of school ecological environment, which includes school space layout (such as site selection, campus planning area, the distribution of school buildings and the classroom layout, etc.) and the physical conditions (such as thermal environment, light environment, sound environment, etc.).
It creates a healthy and comfortable indoor environment by saving resources and energy, maintaining ecological balance and sustainable development of society.

At present in China, most researches on the indoor physical environment and thermal comfort improvement focus on residential and office public buildings rather than colleges and universities teaching building. Teaching buildings in university are the main places for students to acquire knowledge. The quality of the indoor environment is directly related to the students' learning efficiency as well as the physiological and psychological health. Thus, the optimized design study of indoor physical environment for teaching space has important significance to improve the environment.

\section{BASIC SITUATION OF RESEARCH OBJECT}

The research object is the NO.8 teaching building of Southwest Jiaotong University in Chengdu area. Chengdu is located in south of the Tropic of Cancer, 104.06 east longitude, 30.67 latitude. The area is hot in summer and chilly in winter. The change of sun azimuth range is small in winter, which can be ranged from $-63^{\circ}$ to $63^{\circ}$. But the changes of solar radiation between the walls are extremely large. The north wall is unable to receive the sunshine; while south, southeast and southwest walls could get more solar radiation. According to historical statistics, the minimum temperature of campus in winter is around $1^{\circ} \mathrm{C}$. The cold winter usually lasts as long as 3-4 months. Because palisade and ventilation instrument were not installed properly, questionnaire reflects that indoor temperature of the building is significantly lower, teaching areas come into a poor condition. Therefore, improving indoor physical environment and summarizing good design methods to improve the work efficiency is especially important.

\section{A. Planning the layout and structure form of existing buildings}

No.8 Teaching Building is a 6-floor frame structure consisting the classrooms, lecture halls and ancillary office space. There are no shade measures on the surface of the building. The architectural form is shown as Fig. 1. 


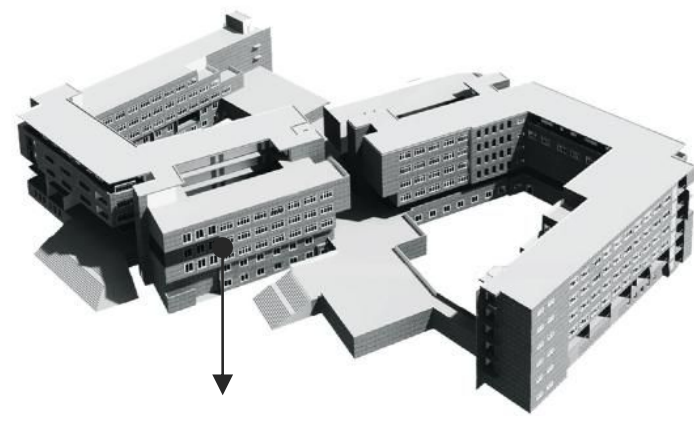

Selected Classroom

Figure 1. Computer simulation model of No.8 Teaching Building

There are no other giant buildings around it that could make any influence on it. Its northwest side faces the lake; its south side connects the road and acts as the main entrances and exits. The classrooms of the whole building's layout are given priority to the $30^{\circ}$ toward south by west. Parts of the classrooms toward east-west. The floor height is 3.6 meters. The wall is made of Clay Hollow Brick. The thickness of the wall is $240 \mathrm{~mm}$. The exterior surface of the external wall is a decorative brick layer, and the surface of it is decorated with paint layer. According to the results of the questionnaire survey, the satisfaction is low for numerous physical classroom environments. We choose the classroom 8432 as the main object in this study. This classroom is located at the southwest corner of the building. The floor plan is shown in figure 2. The plane size of the classroom is 6900 mm*9900 mm. There are six single-layer glass aluminum alloy push-pull windows and two wooden doors. Window size is $1800 \mathrm{~mm} * 1800 \mathrm{~mm}$, high sill is $900 \mathrm{~mm}$, and the gate size is $1000 \mathrm{~mm} * 2000 \mathrm{~mm}$. The two exterior walls and the high windows results in such an uncomfortable environment - hot in summer and cold in winter,

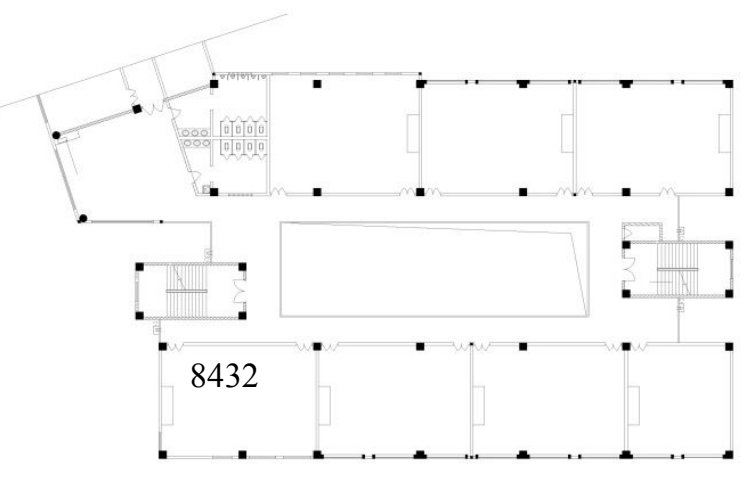

Figure 2. The layout of the classroom

\section{$B$. The measured results of the indoor temperature and humidity in winter}

Thermal environment consists of air temperature, air humidity, thermal radiation intensity and airflow velocity four-parameter component. Those thermal effects caused by building envelop could affect human thermal sensation surroundings. For the teaching building, the physical environment is divided into indoor thermal environment and the outdoor environment. Outdoor thermal environment is an integral part of the outdoor climate. The main function of the outdoor enclosure structure is to resist or take advantage of the outdoor heat the environment.

\section{1) The Test Method}

Multi-point measuring methods are used as the main field measurements for measuring wind speed, relative humidity, temperature and indoor thermal comfort in the teaching space. We select 6 measuring points, which are evenly distributed around the room. Test time is at 12:30 on January 21,2014 to at $12: 30$ on January 22 . The weather is good, sunny with occasional breeze. Test equipment and items are shown in the table.1.

TABLE I. TEST EQUIPMENT AND ITEMS

\begin{tabular}{|c|c|c|}
\hline Test items & Test equipment & parameters \\
\hline Wind speed & $\begin{array}{l}\text { ZROF-F30 } \\
\text { Anemometer }\end{array}$ & $0.05 \sim 30 \mathrm{~s} / \mathrm{m}, \quad \pm 3 \%$ \\
\hline Temperature & $\begin{array}{l}175-\mathrm{H} 2 \text { Automatic } \\
\text { recorder }\end{array}$ & $\begin{array}{l}-\quad 20.0 \\
60.0^{\circ} \mathrm{C} ; \pm 0.5^{\circ} \mathrm{C} \\
\pm 0.1^{\circ} \mathrm{C}\end{array}$ \\
\hline Humidity & $\begin{array}{ll}175-\mathrm{H} 2 & \text { Automatic } \\
\text { recorder } & \end{array}$ & $\begin{array}{l}0.1 \sim 100 \% \mathrm{RH}, \\
\pm 3.0 \% \mathrm{RH} ; \pm 0.1 \% \mathrm{RH}\end{array}$ \\
\hline $\begin{array}{l}\text { Thermal comfort } \\
\text { Indoor }\end{array}$ & $\begin{array}{lr}\begin{array}{l}\text { CASSLER } \\
\text { thermal }\end{array} & \text { LAQ } \\
\text { meter } & \text { comfort } \\
\end{array}$ & $\begin{array}{l}1 \sim 60^{\circ} \mathrm{C}, \quad 0.06 \sim \\
2.50 \mathrm{~m} / \mathrm{s}\end{array}$ \\
\hline
\end{tabular}

2) The Test Result

\section{a) The Air Temperature}

According to the results of the hourly record, raw data and the average hourly temperature are shown in Fig.3.

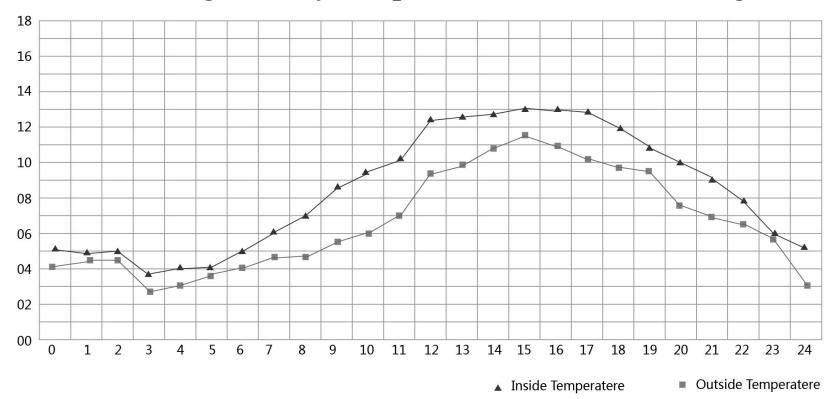

Figure 3. Temperature curve of classroom indoor and outdoor in winter

\section{b) Relative Humidity}

Relative humidity curve are shown in Fig.4.

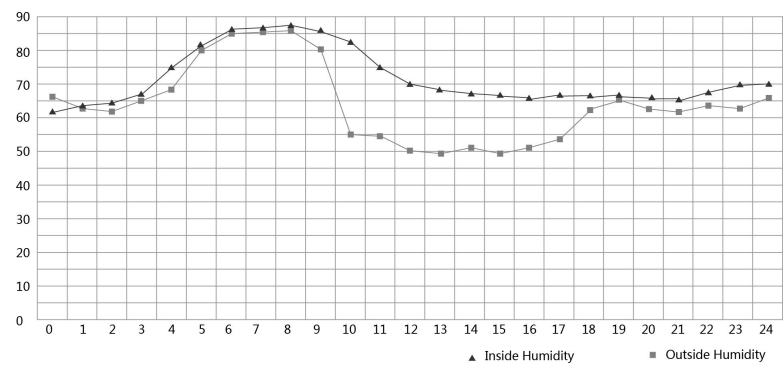

Figure 4. Relative humidity curve of classroom indoor and outdoor in winter

During the test period, the average outdoor temperature was $5.7^{\circ} \mathrm{C}$. Minimum temperature is $3{ }^{\circ} \mathrm{C}$ at around 3:00, and the maximum temperature of $9.5^{\circ} \mathrm{C}$ was shown at about 14:00. The trend of the indoor and outdoor temperature was similar, as the Fig. 3 shows. The mean radiant temperature ranged from 8.3 to $13{ }^{\circ} \mathrm{C}$ with an 
average value of $10.7{ }^{\circ} \mathrm{C}$. Temperature peak appeared at times, and the upward trend was slow at midday temperature period.

\section{c) Mean Radiant Temperature}

The average radiation temperature refers to the average temperature that the environment around the surface radiation affects to human body. Radiant heat exchange between the body and the surface of the envelope depends on the relative positional relationship between the surface and human, as well as the temperature of each surface. The inside surface temperature of the envelope in actual environment varies and not be uniform, such as the inner glazing surface temperature of the winter is much lower than the inner wall surface. Distance and direction between man and the window directly affect the heat loss of the body. Therefore, the radiation heat transfer between human body and the surrounding wall has a great influence on people feeling of hot and cold. The computation formula is as follows:

where $t_{n}=$ wall temperature; $S_{\mathrm{n}}=$ wall surface area.

Organize all data in Fig.5.

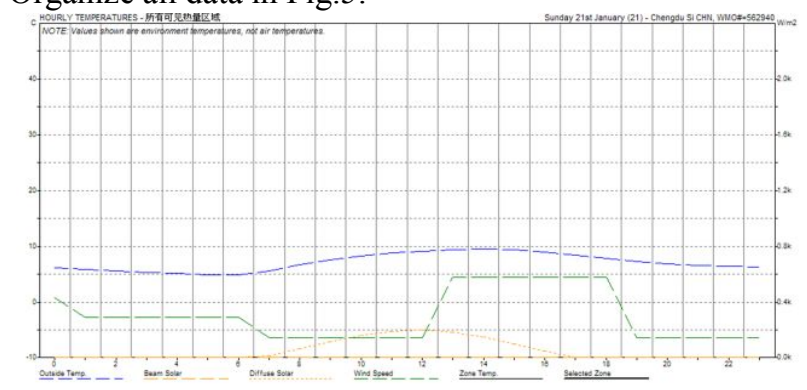

Figure 5. All the measurement variation, January 21

3) The Analysis of The Indoor Temperature and Humidity Measurement Data in Winter

According to the measured data we can summarize the following features:

First, winter in Chengdu area is very chilly. Average temperature is lower than $6{ }^{\circ} \mathrm{C}$. Relative humidity of air is very high, and the average relative humidity is higher than $80 \%$.

Second, the indoor temperature is very low. The average temperature is about $6{ }^{\circ} \mathrm{C}$. When it's sunny, the outdoor temperature rises quickly, however indoor temperature's rise is not big, which leads to the students prefer to stay outside when the weather is good.

Third, the classroom indoor air humidity is very large, and the average relative humidity is around $85 \%$, very damp. To a certain extent, it will feel colder.

Fourth, on the surface of the ground, floor and wall temperature is lower, and the average temperature of $5^{\circ} \mathrm{C}$. Cold radiation phenomenon is obvious.

Fifth, the difference between surface temperature of the palisade structure inside and outside is small, even less than $1{ }^{\circ} \mathrm{C}$, which means that the envelope insulation of the measured teaching building performs very poor.

Specific analysis of the causes is to be considered. The cold winter in Chengdu, the weak solar radiation and the poor building envelope thermal performances result in the low indoor temperature. And it is difficult to meet the thermal comfort requirements. Since Chengdu is located in the south of the Yangtze, it doesn't have central heating in winter. Classroom is commonly used electric heating as the local heating mode, which can only warm a few bodies. The indoor temperature and the surface temperature of the envelope cannot be effectively improved. The entire indoor thermal environment has not been significantly improved. It can be said teaching indoor thermal environment in Chengdu is quite harsh in winter as workers often feel very cold and uncomfortable indoors.

\section{STUDY ON IMPROVING MEASURES}

To solve the above problems of existing buildings, we choose ecotect analysis software as an analytical tool, the "hot summer and cold winter area building energy efficiency design standards" as the standard. From the viewpoint of heat resistance, radiation and other factors, we improve the overall planning of research building and retain structure materials and forms.

\section{A. 3.1 The Orientation and Morphology}

\section{1) The Orientation Factor}

As the best orientation of the building in Chengdu area shown in Fig.6, you can see the main classroom of No.8 teaching building is not among the best orientation range. The current orientation of the No.8 teaching building will cause the waste of indoor solar radiation in the winter. Therefore, the selection of the base should follow a few suggestions:

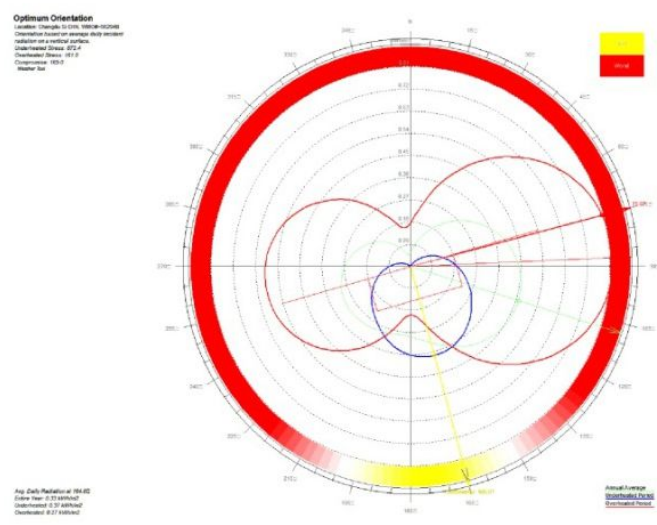

Figure 6. The best toward of buildings at Chengdu

First, the building should take the best orientation, to improve the thermal environment quality of the main room. Considering the summer sunshade, east and west should not be used as the main orientation, that is the main classroom can be considered the main orientation from the southeast to south to get more solar radiation to use in the winter.

Second, auxiliary rooms can be put the poor orientation, such as north, which is lack of solar radiation or west, which is intense solar radiation.

Third, it should be controlled about the construction of complex shape, to avoid unnecessary blocking and ensure the winter solar radiation. In the analysis of the test object, its winter solar radiation time on the vertical wall area is too short, which is less than two hours, the indoor environment cannot get enough solar radiation. By analyzing the direction of the arrow can be drawn the best direction, the $75.07^{\circ}$.

2) The window wall area ratio 
The window wall area ratio refers to the ratio of the window hole and room facade unit area. Heat consumption outside the window is usually 5 to 20 times of the façade per unit area. Therefore, to minimize the area outside the window, especially something out the window, is necessary. Japanese energy-saving buildings of the window to wall ratio has decreased to $10 \%$. While China stipulates that different orientations window wall area ratio should not exceed the following values: 0.25 north, east to $0.30,0.35$ to the south

\section{3) Shape Coefficient}

Shape coefficient means the volume ratio of the building and outer surface enclosed. In various parts of the building envelope heat transfer coefficient and window wall area ratio unchanged, heat consumption index increased linearly with the shape coefficient, and point clearly not conducive to energy conservation. Similarly, the smaller the building area is, the smaller the air conditioning load is. The study shows that it is the most energy-saving when the building shape coefficient is 0.15 . Taking into account the actual situation, "energy standards" 4.1 .2 provision, building shape coefficient should be controlled at 0.30 or 0.30 or less, If the body coefficient greater than 0.30 , the roof and exterior wall insulation should be strengthened.

\section{B. Improving the building envelope}

After comparing strengths and weaknesses in the different methods, we summarize conductive design approach of the building envelop in Chengdu. Specific components as follows:

\section{1) Wall Insulation}

There are mainly three methods which are used for the building exterior wall thermal insulation: internal thermal insulation, external thermal insulation, internal and external mixing method. Exterior insulation is to placethermal insulation system outside facades, what's more give the building good thermal insulation properties and building energy-saving measures. Since the insulation system placed on the outside, so that the temperature difference which the main structure suffered declined significantly, also the temperature deformation reduced. Thus the wall exterior insulation protect the structure of the wall. And effectively block the cold (hot) bridge structure, which is conducive to longevity, to increase the thermal resistance of the outer wall and raising the indoor temperature.

At present in China, for the wall heat preservation,expanded polystyrene foam plastic insulation board (EPS), paste or mechanical fix on brick wall are mainly used to form external thermal insulation layer structure. But there are problems with this kind of structure in the construction of colleges and universities, such as the follows:

First, do not set drainage construction measures in stormy weather, because the rain into it will not discharge well.

Second, set surface-sealing type measures without providing equal pressure node configuration, In stormy weather, rain may enter the insulation layer, the adhesive force of the insulation board decline, damp the insulation board. Durable for a long time to use this structure, we must adopt as pressure such as node or rain structure.
Third, moist vapor barrier has not been setgenerally, thus moisture easily enters through the insulation layer. The water or water vapor can make the bond strength decline between the layers of the structure; also affect the durability of the structure.

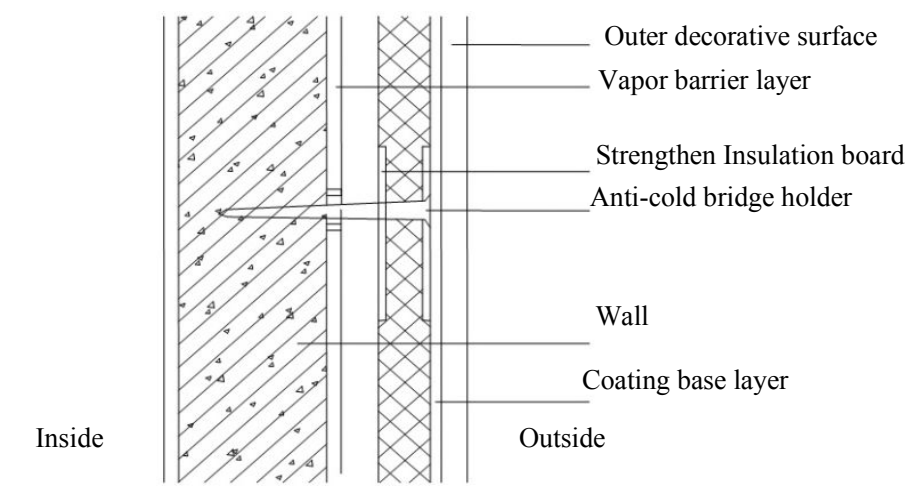

Figure 7. The wall structure schematic

The above issues being comprehensively considered, the following improvements are put.

Foremost, setting vapor barrier on the layer outside the building will prevent insulation from moisture or condensate produced in it.

Secondly, there is a certain gap between polystyrene insulation board and vapor barrier. Set up a metal pan of water in the lower part of each level will ensure thermal performance of insulation materials, furthermore improve the durability of the insulation material.

Thirdly, the seam of the insulation board is equipped with two insulation sealing line rods. By air pressure between two heat seal bars lining, both to ensure the seams impermeable and the seams do not produce cold air infiltration.

Fourth, horizontal metal pan of water can play a role in firebreak, meanwhile,the rain and condensation water is discharged from inner structure into outside.

2) Doors and Windows Insulation

Doors and windows are less thermal resistance in the palisade structure of the building. The heat preservation and heat insulation performance of Windows and doors is also a key to improve indoor comfort.

Hot summer and cold winter areas:

Window heat transfer coefficient $\mathrm{K} \leq 3.2 \mathrm{~W} /\left(\mathrm{m}^{\wedge} 2, \mathrm{~K}\right)$, window visible light transmittance $\zeta \geq 40 \%$,

Window shading coefficient of $\mathrm{Se} \leq 0.6$;

Airtight performance q $1 \leq 1.5 \mathrm{~m}^{\wedge} 3 /(\mathrm{m} \bullet \mathrm{h})$

The doors and windows lost energy in fore ways:radiativetransfer, convection, conduction transfer and air leakage.

Specific to the glass selection to improve the problem, heat transfer coefficient $\mathrm{K}$ of the glass, means under the condition of steady heat transfer, glass on both sides of the air temperature difference is $1{ }^{\circ} \mathrm{C}$, the unit time by $1 \mathrm{~m}^{\wedge} 2$ hollow glass heat transfer, show as $\mathrm{W} /\left(\mathrm{m}^{\wedge} 2, \mathrm{~K}\right) . \mathrm{K}$ value is lower, the better the performance of heat preservation and heat insulation of hollow glass, when use of the energy saving effect is significant.

Firstly, according to the regional standards to choose the appropriate energy-saving Windows and doors $\mathrm{K}$ value, 
which on the high side cannot achieve energy efficiency standards, while low the cost is higher.

Secondly is reasonable doors and Windows system selection.Do not choose push-pull system.

Thirdly, select the similar $\mathrm{K}$ value of insulated aluminum and hollow glass, otherwise it will produce condensation.

Forth, properly select heat insulation aluminum to never have a "cold bridge" phenomenon. At the same time it should be selected the appropriate heat insulation aluminum $\mathrm{K}$ value to prevent condensation phenomena.

\section{3) Roof Regenerative}

Adding regenerative device on the roof,which could absorb solar radiation during the day and distribute heat to board room at night, improves the indoor comfort.

\section{INDOOR COMFORT DESIGN SUGGESTIONS}

Chengdu belongs to the climatic zone, which is in the hot summer and cold winter zone of China, indoor comfort design requires meet the demand of summer heat, while an appropriate balance with winter insulation.In order to improve the thermal capability, we should increase the resistances of outer wall, the height of the window and the thermal capabilityof roof. Also could use highly efficient thermal insulation materials in composite wall,and selectgood insulation properties of new glass. The window should have a good seal and shading to meet the requirements of good thermal stability in winter as well as summer.

\section{REFERENCES}

[1] Jinghua Yu, Liwei Tian, Changzhi, Yang, Xinhua Xu, Jinbo Wang. Sensitivity analysis of energy performance for high-rise residential envelope in hot summer and cold winter zone of China[J].2013

[2] Anupama Sharma,Richa Tiwari. Evaluation of data for developing an adaptive model of thermal comfort and preference[J]. The Environmentalist . 2007 (1)

[3] H. Yoshino,S. Guan,Y.F. Lun,A. Mochida,T. Shigeno,Y Yoshino,Q.Y. Zhang. Indoor thermal environment of urban residential buildings in China: winter investigation in five major cities[J]. Energy \& Buildings . 2004 (12)

[4] ASHRAE.Thermal environmental conditions for human occupancy. ANSI/ASHRAE55-2004 . 2004

[5] Luyi Xu,Junjie Liu,Jingjing Pei,Xu Han. Building energy saving potential in Hot Summer and Cold Winter (HSCW) Zone, ChinaInfluence of building energy efficiency standards and implications[J]. Energy Policy . 2013

[6] Li T,Ni JF,Zhang K,Yao J.Effect of Building Orientation on Energy Consumption in Hot Summer and Cold Winter Zone. 2011 International Conference on Machine Intelligence (Icmi 2011 ) 2011

[7] Nasim A.Mullen,Seema Bhangar,William W Nazaroff,Nathan M.Kreisberg,Susanne V.Hering. Heated Surfaces Contribute to Indoor Ultrafine Particle Exposures[A]. The First International Conference on Building Energy and Environment Proceedings[C] 2008

[8] Analysis on Green Building Materials-Humidity Adjusting Materials[A]. Proceedings of 2011 International Conference on Materials for Renewable Energy \& Environment(ICMREE 2011) VOL.01[C]. 2011

[9] YU Xiao-ping. The research on fresh-air energy consumption and the cooling and dehumidification methods in residential buildings in hot summer and cold winter zone. . 2000

[10] U.S.Green Building Council.LEED green building rating system TM. . 2009 